\title{
Virtual World to Motivate Learning: Exploring Arabic EFL Learners' Views Toward Utilizing the Second Life Virtual Game as a Motivational Tool
}

\author{
Ebrahim Bamanger* \\ Curriculum and Instruction, King Saud University, Saudi Arabia \\ Amani Gashan \\ Curriculum and Instruction, King Saud University, Saudi Arabia
}

\begin{abstract}
This study was intended to explore EFL learners' views toward the use of the virtual Second Life game as a motivational instructional tool, their opinions on its technical use, and any obstacles they face while using this technology. The participants of the study were forty-one EFL Arab students who were enrolled in English language mainstream of the bachelor's degree at a school of education in the capital city of Riyadh, Saudi Arabia. At the end of a computer-assisted language learning course exploring the Second Life virtual game, they were asked to complete a questionnaire to gather descriptive data regarding the questions of the study. The results indicated that these EFL learners hold positive views toward the use of the Second Life game as a motivational tool in language learning, although there are some concerns regarding the availability of the necessary technology skills to use the game. The most notable recommendation from the study highlighted the need for teacher encouragement to use digital games to practice the foreign language.
\end{abstract}

Keywords: EFL learner, views, motivation, Second Life, language learning, virtual life

DOI: $10.7176 /$ JLLL/63-06

Publication date: December $31^{\text {st }} 2019$

\section{Introduction}

Second language acquisition (SLA) research has long highlighted the importance of interaction as one of the valuable factors in language acquisition (Sykes \& Reinhardt, 2013; Alshumaimeri, Gashan, \& Bamanger, 2019). Over the last several decades, innovations in technological tools have supplied language learners with access to richer sources of a second language (L2) for their target language interaction. The Internet is a nearly limitless source of videos, magazines, news, and websites that are accessible in almost all the spoken languages. Websites, such as Livemocha, Italki, and Lang- 8 have emerged that are developed precisely to support those interested in learning languages. Some of these resources can connect a language learner to a fluent native speaker to offer the opportunity to practice a second or a foreign language's skills in both text or speech format.

Outside their instructional setting, foreign language learners find it difficult to get any chance of engagement in interactive use of the target languages. If a student learning a foreign language lives in a community where there are no native speakers of that target language (outside of his/her classroom setting), then any opportunities to use that language will be scarce. According to Fageeh (2011), Arab EFL learners typically get inadequate exposure to use the foreign language and interact with native speakers. Even for a foreign language learner who lives in a community surrounded by native language speakers, real interaction opportunities could be limited because the foreign language learner may feel that his/her language skills are not adequate to keep up with the native users of the target language.

A recommended strategy to solve this challenge is to provide Arab EFL learners with a place for target language interaction. Such places should be informal, have a nature that eliminates social hierarchies, and stimulates conversation among the participants. Hassan, Dzakiria, and Idrus (2015) believe that employing Second life could help in facilitating and sustaining a virtual community. They argue that several educational institutes have started to offer courses using Second Life to enhance learners' language skills because Second Life offers an interactive, engaging platform that simulates real-life experiences and presents authentic practices. EFL learners in communities where English is not spoken usually fail to get adequate exposure to authentic social and cultural experiences within their educational circumstances; however, multiuser virtual environments (MUVEs) might be able to bridge such gaps.

Some valuable benefits of the Second Life environment, compared to the traditional EFL classroom, includes the mechanism to encourage active learning participation; the ability to offer an environment for language and cultural involvement with numerous interactive media and a rich sense of context for learning (Warburton, 2009); and the potential of reducing students' nervousness, which may be apparent in some "traditional" classrooms.

Calls for integrating technological tools into EFL learning and instruction are backed by the extensive 
literature on Computer Assisted Language Learning (CALL) and Mobile Language Learning (MALL), encouraging technology integration as a language learning approach (Alshumaimeri \& Bamanger, 2013; Bamanger \& Alhassan, 2015). Research interest in game-based computer-assisted learning has grown dramatically in the last few decades (Hwang \& Wu, 2012), and these methods have become extremely popular for helping learners enhance their engagement and motivation. With the rapid growth of technological tools, it becomes applicable to incorporate such technological tools in the educational process. Therefore, Second Life should be further explored as a critical educational tool because this technology is capable of merging individuals from all over the world.

\subsection{Views Towards Digital Games}

Games in classrooms are no longer viewed as only for fun, but instead seen as instructional instruments with the potential to engage students' interests and immerse them in subject-knowledge. The incorporation of games in an educational context has become increasingly popular. However, some may perceive games as simply full of violent content that several students and teachers may believe game-playing as useless and even harmful. Games may not be seen as a welcome tool in several educational contexts due to this perception. On the other hand, if learners and their teachers perceive playing digital games more positively, then it is probable that they will engage in online games-based language instruction. Noraddin and Neo Tse (2015) found that the majority of Malaysian university teachers have positive views toward integrating digital games in their classrooms. If research subjects play digital games as a lifestyle habit, this could show an association with a positive view. In other words, those who play digital games themselves are more likely to have positive views toward using those games for education.

Dourda, Bratitsis, Griva, and Papadopoulou (2014) proposed an educational design that combines two wellestablished teaching approaches, Game-based Learning (GBL) and Content and Language Integrated Learning (CLIL). The context of the proposal was the design of an educational geography computer game, utilizing QR codes and Google Earth for teaching the English language to Greek primary school students. The researchers argued that this integration provides a motivational and cognitive basis for language learning, since it represents a meaningful, contextualized activity and, on the other hand, gives students the chance to expand their cognitive skills and use a more sophisticated language. The findings of this case study suggested that foreign language learning can successfully take place within a geography game-based learning environment and underscore the efficacy of approaching GBL in terms of performance. Overall, students showed positive views towards the game, and the post-test results were significantly improved compared to the pre-test in terms of vocabulary acquisition and reading skills in the foreign language and geography knowledge.

\subsection{Second Life and Motivation}

As technology advances, it is recommended that instructors integrate technological tools into their innovative instructional approaches. Using virtual world platforms can be a good alternative to traditional teaching methods because it can provide richer learning experiences (Wyss, Lee, Domina, \& MacGillivray, 2014). Individual learners' motivation to learn a language can impact greatly the speed of their second language acquisition, and motivation is argued to be the strongest predictor of success (Gass \& Selinker, 2001). Playing an online game fosters an environment in which motivation is present, and Dixon (2014) argued that motivation could be achieved in the online gaming culture. According to Peterson (2010), online games offer motivating contexts that encourage engagement with active forms of the target language interaction. Motivation is a key element of learners' success, and employing digital games can provide a valuable means of synchronous communications and social interactions that can increase learners' motivation to learn through this medium (Delucia, Francese, Passero, \& Tortora, 2009; Noraddin \& Neo Tse, 2015).

Rahim (2013) indicated that engaging in Second Life can have positive impacts on users' learning, motivation, and attitudes toward the learning process. He also concluded that the interactive 3D environment within Second Life can promote learner-centered teaching by enabling learning to be more interactive and attractive; thus, it can enhance students' motivation to study and develop their abilities to acquire related problem-solving abilities. Papastergiou (2009) suggested that digital games could be implemented to create a motivational learning environment after seeing an increase in students' learning level of motivation. Similarly, the digital game seemed to have given learners greater enthusiasm to study a greater amount of knowledge regardless of the student's gender.

There have been a number of studies investigating the potential for virtual world games as language learning tools, and some have found positive results regarding their use to motivate language learners. Literature shows that those games could be low-stress activities that second language learners can use to engage in the target language in a rich-input and authentic language use environment. 


\subsection{Statement of the Problem}

Before any conclusions can be arrived at about the usefulness of digital games for foreign language learning motivation, more research is needed, specifically in the Arabic context. Several studies have used World of Warcraft as their medium game, and there is a need for further research to be conducted with different games. Thus, the current study was conducted to explore the use of the Second Life game as a tool of English language learning in the Arabic context.

According to Hwang and Wu's review (2012), there is a lack of research related to the use of digital games for learning in the Middle East Arab countries. This raises the question of where undergraduate learners in the Arabic context stand with regard to the idea of integrating virtual life games as a means of learning in higher education? The exploration of the use of Second Life in language learning is still in its infancy in the Arabic context, and only one study has been conducted in this field (Aldosemani \& Shepherd, 2014) with a focus on the cultural use of the game and using a qualitative method.

\subsection{Research Questions}

This study was guided by the following questions:

1. What are Arab EFL learners' opinions regarding the use of the Second Life game as a motivational tool?

2. What are the Arab EFL learners' opinions regarding the technical use of the Second Life game?

\subsection{Objectives of the Study}

The main purpose of this study was to gain a better understanding of the usefulness of online digital games for promoting foreign language acquisition in Saudi Arabia and aimed to achieve the following goals:

1. To reveal valuable information regarding the use of Second Life as a motivational tool.

2. To reveal valuable information regarding the technical use of Second Life in EFL classes.

\subsection{Significance of the Study}

This study explored the potential of using the Second Life game as a supplementary language learning source and to find out learners' attitudes toward and readiness to use it. The findings will be beneficial to give decisionmakers a clear picture of the incorporation of digital games in the language learning field to help in developing language learning and to raise the level of EFL teachers and learners' ability to use these innovative instruments.

\section{Research Methodology}

\subsection{Participants}

The subjects were forty-four EFL undergraduate students who were enrolled in the English language bachelor's program at a school of education in one of the public Saudi universities in Riyadh. Forty-one of the subjects successfully responded to the study instrument. In addition to the English language and teaching methods, the participants were taking a computer-assisted language learning course in which they learned how to make use of innovative technology tools to teach foreign languages. Their first language was Arabic, and they used it as the only communicative tool in their daily life with very limited usage of English.

\subsection{Data Collection Instrument}

A descriptive research design was implemented utilizing a quantitative questionnaire developed by the researchers to investigate EFL Arab learners' views toward the utilization of the Second Life virtual Game as a motivational tool and its technical use. The tool was built within a larger project to explore the integration of Second Life in EFL classes after reviewing the previous literature. Later, the questionnaire was reviewed by a group of specialists in language education, curriculum, and teaching methods, and the validity and reliability were checked. The Cronbach's alpha coefficient was reported to be 0.773 for the first dimension exploring the Second Life as a motivational tool and 0.750 for the second dimension investigating the technical use of the game (Second Life). The Pearson correlation coefficient $(0.879 \& 0.603)$ were found to be positive and significant at $(\mathrm{Sig}=0.01$ level) for the two dimensions, and both are regarded as high values.

Both dimensions have six items each, and each item is measured on a 5-point Likert-type scale. The participants were asked to respond to each item as: (1) strongly disagree, (2) disagree, (3) no idea, (4) agree, (5) strongly agree, in which a higher score means stronger agreement.

\subsection{Procedure}

The participants were introduced to the Second Life game, an online virtual world game developed by Linden Lab. The learners can create, connect, and chat with others from around the world. It is a free game in which participants are called residents who can create virtual representations of themselves, called avatars. They are able to interact with places, objects, and other residents in the virtual world and participate in social activities. The participants joined the game in the first two weeks of the semester via http://secondlife.com/ and created 
free private accounts. The learners were assisted in helping them to explore the virtual world and create their own avatars, navigate the world, and utilize the game functions. The participants then were instructed to achieve some tasks each week, such as traveling to an English-speaking county and interact with the target language speakers. They also were given tasks to gather cultural information by communicating with native speakers. In the last weeks of the semester, participants were asked to voluntary participate in the study questionnaire about the use of the Second Life virtual game as a motivational tool.

\subsection{Data Analysis}

The responses were analyzed to answer the research questions using SPSS (Statistical Package for Social Sciences) to gather descriptive statistics in terms of the mean, frequency, and the percentage for each item of the study instrument.

\section{Results}

3.1 Research Question 1

What are the Arab EFL learners' opinions regarding the use of the Second Life game as a motivational tool? The participants' responses regarding the first dimension were analyzed in order to answer the first question.

Table 1. Frequencies, percentages, means, standard deviations of participants' responses regarding Second Life (SL) as a motivational tool.

\begin{tabular}{|c|c|c|c|c|c|c|c|c|c|c|c|c|}
\hline \multirow[t]{2}{*}{ Statement } & \multicolumn{2}{|c|}{$\begin{array}{l}\text { Strongly } \\
\text { Disagree }\end{array}$} & \multicolumn{2}{|c|}{ Disagree } & \multicolumn{2}{|c|}{ Not sure } & \multicolumn{2}{|c|}{ Agree } & \multicolumn{2}{|c|}{$\begin{array}{l}\text { Strongly } \\
\text { Agree }\end{array}$} & \multirow{2}{*}{ M } & \multirow{2}{*}{$\mathrm{SD}$} \\
\hline & $\mathrm{F}$ & $\%$ & $\mathrm{~F}$ & $\%$ & $\mathrm{~F}$ & $\%$ & $\mathrm{~F}$ & $\%$ & $\mathrm{~F}$ & $\%$ & & \\
\hline $\begin{array}{l}\text { Using (SL) based learning can } \\
\text { increase self-esteem and } \\
\text { confidence and make me an } \\
\text { independent learner. }\end{array}$ & 0 & 0 & 0 & 0 & 13 & 31.7 & 15 & 36.6 & 13 & 31.7 & 4.00 & 0.806 \\
\hline $\begin{array}{l}\text { (SL) game can bring fun and } \\
\text { enjoyment to learning. }\end{array}$ & 0 & 0 & 1 & 2.4 & 5 & 12.2 & 19 & 46.3 & 16 & 39.0 & 4.22 & 0.759 \\
\hline $\begin{array}{l}\text { I think using (SL) for learning } \\
\text { gives an added motivation to } \\
\text { study. }\end{array}$ & 0 & 0 & 2 & 4.9 & 9 & 22.0 & 16 & 39.0 & 14 & 34.1 & 4.02 & 0.879 \\
\hline $\begin{array}{l}\text { I learn English because I want } \\
\text { to understand the content in } \\
\text { (SL) }\end{array}$ & 2 & 4.9 & 9 & 22.0 & 15 & 36.6 & 5 & 12.2 & 10 & 24.4 & 3.29 & 1.209 \\
\hline $\begin{array}{l}\text { Learning language skills } \\
\text { through (SL) games is quite } \\
\text { interesting. }\end{array}$ & 0 & 00.0 & 1 & 2.4 & 10 & 24.4 & 17 & 41.5 & 13 & 31.7 & 4.02 & 0.821 \\
\hline $\begin{array}{l}\text { I found playing this game } \\
\text { more fun than traditional } \\
\text { teaching methods. }\end{array}$ & 0 & 0 & 5 & 12.2 & 9 & 22.0 & 11 & 26.8 & 16 & 39.0 & 3.93 & 1.058 \\
\hline
\end{tabular}

The findings from the above table indicate that the means of five out of six items were in the high range (5 $3.5)$, with only one item in the average range $(3.4-2.5)$. The second statement, "(SL) game can bring fun and enjoyment to learning" was in the most highly rated among the items in the dimension exploring students' opinions regarding the use of SL game as a motivational tool, with a mean of 4.22. This indicates that there was agreement among the members of the study sample that the Second life game would bring pleasure into the learning process.

The third and fifth items, "I think using (SL) for learning gives an added motivation to study" and "Learning language skills through (SL) games is quite interesting," were in second place with a mean of 4.02, which reflects that there was agreement among the study sample that the Second Life game could bring interest into learning and added motivation to education process.

The first item in the list, "Using (SL) based learning can increase self-esteem and confidence and make me an independent learner," took the third rank among the items with a mean of 4.00. More than two-thirds of the sample agreed (36.6) or strongly agreed (31.7\%) that using the Second Life game can increase self-reliance and confidence and help them to be independent learners. The remaining third $(31.7 \%)$ were unsure about this statement, with no participants showing disagreement.

The results also showed that the sixth item in this dimension was in fourth place with a mean of 3.93, where nearly two-thirds of the participants agreed or strongly agreed that playing SL was more fun than the traditional teaching methods. However, 22\% were uncertain, and 12.2\% disagreed. Finally, the fourth item, "I learn English because I want to understand the content in $(\mathrm{SL})$," was the least-highly rated $(\mathrm{M}=3.29)$, with only $36.6 \%$ either 
agreeing or strongly agreeing. The same percentage $(36.6 \%)$ showed neutral opinions, and $22 \%$ disagreed with this statement.

\subsection{Research Question 2}

What are the Saudi learners' opinions regarding the technical use of Second Life? Exploring the technical use of the game was achieved via the use of the second dimension of the questionnaire. As illustrated in the table below, six items were devoted to investigating the learners' opinions regarding the ease of the game, as well as any possible obstacles.

Table 2. Frequencies, percentages, means, standard deviations of participants' responses regarding technical elements of Second Life (SL)

\begin{tabular}{|c|c|c|c|c|c|c|c|c|c|c|c|c|}
\hline \multirow[t]{2}{*}{ Statement } & \multicolumn{2}{|c|}{$\begin{array}{l}\text { Strongly } \\
\text { Disagree }\end{array}$} & \multicolumn{2}{|c|}{ Disagree } & \multicolumn{2}{|c|}{ Not sure } & \multicolumn{2}{|c|}{ Agree } & \multicolumn{2}{|c|}{$\begin{array}{l}\text { Strongly } \\
\text { Agree }\end{array}$} & \multirow{2}{*}{ M } & \multirow{2}{*}{ SD } \\
\hline & $\mathrm{F}$ & $\%$ & $\mathrm{~F}$ & $\%$ & $\mathrm{~F}$ & $\%$ & $\mathrm{~F}$ & $\%$ & $\mathrm{~F}$ & $\%$ & & \\
\hline $\begin{array}{l}\text { The graphic design of the } \\
\text { game attracts me. }\end{array}$ & 0 & 00.0 & 6 & 14.6 & 15 & 36.6 & 14 & 34.1 & 6 & 14.6 & 3.49 & 0.925 \\
\hline $\begin{array}{l}\text { The instructions/hints in the } \\
\text { game are clearly given. }\end{array}$ & 0 & 00.0 & 4 & 9.8 & 17 & 41.5 & 13 & 31.7 & 7 & 17.1 & 3.56 & 0.896 \\
\hline $\begin{array}{l}\text { Yes, I did play the game, } \\
\text { and I think it was a little } \\
\text { hard. }\end{array}$ & 20 & 48.8 & 9 & 22.0 & 6 & 14.6 & 4 & 9.8 & 2 & 4.9 & 2.00 & 1.225 \\
\hline $\begin{array}{l}\text { I think I have the necessary } \\
\text { technology-related skills to } \\
\text { use the game. }\end{array}$ & 5 & 12.2 & 9 & 22.0 & 9 & 22.0 & 14 & 34.1 & 4 & 9.8 & 3.07 & 1.212 \\
\hline $\begin{array}{l}\text { My teacher encourages the } \\
\text { use of digital games in } \\
\text { language teaching. }\end{array}$ & 21 & 52.5 & 14 & 35.0 & 5 & 12.5 & 0 & 0 & 0 & 0 & 2.59 & 1.024 \\
\hline $\begin{array}{l}\text { The game was easy to } \\
\text { control. }\end{array}$ & 4 & 9.8 & 4 & 9.8 & 12 & 29.3 & 16 & 39.0 & 5 & 12.2 & 3.34 & 1.132 \\
\hline
\end{tabular}

The second item for this dimension was in the first place with the highest mean of 3.56, where almost half of the participants $(48.8 \%)$ either agreed or strongly agreed that the instructions of the game were clearly given, while some of the participants $(41.5 \%)$ were uncertain about the statement. The first item, related to the attraction of the graphic design of the game, was in second place with a mean of 3.49, where more than one-third of the participants (48.7\%) agreed or strongly agreed about the attractiveness of the design.

The sixth item, "The game was easy to control," took the third rank with a mean of 3.34, which indicates that $39.0 \%$ of the participants agreed that the Second Life game was easy to play. However, $29.3 \%$ of the participants expressed uncertainty regarding this point, and almost $18 \%$ either disagreed or strongly disagreed.

With a mean of 3.07, the fourth item, "I think I have the necessary technology-related skills to use the game," was in the fourth place. The findings related to this item showed that $43.9 \%$ of the participants either agreed or strongly agreed that they had enough technology-related skills to use the game, while some of the participants $(34.2 \%)$ voted for disagreement, and $22 \%$ expressed uncertainty about this statement.

With an average mean score of 2.59, the fifth item in the list, "My teacher encourages the use of digital games in language teaching," was in the fifth place. More than half $(52.5 \%)$ of the study sample strongly disagreed, and $35.0 \%$ disagreed that their teachers encouraged them to use this digital game to practice a second language. Finally, the third item on the list, "Yes, I did play the game, and I think it was a little hard," was in the last place with a low mean of 2.00. Almost half (48.8\%) of the participants strongly disagreed, and $22 \%$ disagreed that they found the game hard when they played it.

\section{Discussion}

This study investigated Arab EFL learners' opinions about using virtual games (Second life) as a motivational language learning tool and their views regarding the technical use of Second Life. The participating EFL learners in the study expressed generally positive views towards the use of the Second Life game as an effective tool for motivation.

Research studies ( Dixon, 2014; Gale, 2011; Peterson, 2010; Rahim, 2013; Rosman et al., 2013; Wyss, et al., 2014; $\mathrm{Wu}$, et al., 2014) have revealed that digital games that combine a variety of audio, digital, and multimedia images are effective in motivating learners and at the same time, enhancing their technology skills. The sample in the present study agreed that the Second Life game can bring fun and enjoyment to learning. Most of them also thought that the use of SL for learning could give added motivation to study and that learning language skills through SL is quite interesting. Peterson (2010) argued that online games foster an environment that offers 
a motivating context eliciting engagement in useful forms of target language interaction. Moreover, Kirriemuir and McFarlane (2004) found that motivation is one of the key reasons for choosing to adopt digital game-based learning and that this motivation factor can also bring fun and academic achievement to the learning process.

Almost two-thirds of the participants in the current study agreed that the use of the Second Life game can increase self-reliance and confidence and help them to be independent learners. Similarly, they agreed that playing SL is more fun than traditional teaching methods. Rahim (2013) that Second Life has positive effects on motivation towards learning and he also concluded that the interactive 3D environment within Second Life promotes learner-centered teaching by enabling learning to be more engaging, fun and interesting, thus increasing students' motivation to learn.

Consistently, Ertzberger (2009) and Gale (2011) argued that digital games can be the right tool to engage and motivate learners in classrooms. Furthermore, Papastergiou (2009) suggested that digital games could be implemented to create an effective and motivational learning environment. This study confirmed an increase in the students' learning motivations.

Regarding the second question that explored the technical use of Second Life, almost half of the participants agreed that the instructions of the game were clearly given while some of the participants were uncertain. In addition, the majority agreed about the attractiveness of the design and that the Second Life game was easy to play.

Prensky (2001), DeLucia et al. (2009), and Sanchez (2007) argued that today's students are able to adjust to the SL learning environment easily because they have grown up using computers, digital games, the Internet, and other digital technologies. Although studies found SL a promising tool for assisting language learning, they also disclosed problems that would affect the instructional use of SL. Students might still have difficulties in navigating and using SL's three-dimensional interface (DeLucia et al., 2009; Sanchez, 2007). Unfortunately, in the current study, about half of the sample was not sure if they had the necessary technology-related skills to use the game. Similarly, Ho, Rappa, and Chee (2009) noted that there might be some problems with SL regarding control and learners' unfamiliarity. Moreover, more than half $(52.5 \%)$ of the study sample strongly disagreed, and more than one-third disagreed that their teachers encouraged them to use this digital game to practice a second language. Further, almost half $(48.8 \%)$ of the participants strongly disagreed, and $22 \%$ disagreed that they found the game hard when they played it. In the same line, Rogerson, Nie, and Armellini (2012) found that SL requires a steep learning curve for learners and teachers alike. Grant and Clerehan (2011) concluded that learners expect more explicit directions from their teacher. According to Cooke-Plagwitz (2008), SL requires a considerable investment of time and energy on the part of foreign language teachers.

Overall, the participating EFL learners expressed agreement about the use of this virtual game in enhancing motivation. In general, the results were consistent with those previously reported in studies related to the use of online games. However, there are some concerns regarding the availability of the necessary technology-related skills to use the game. Notably, most of the participants highlighted the need for teacher encouragement to use digital games to practice the foreign language.

The findings of this study indicated that integrating technology into education can be an efficient instructional tool, and it seems that there is an obvious need for prepared EFL teachers who are able to use virtual games effectively when teaching the target language within its culture and in an authentic manner. Moreover, the need for continuous training for EFL teachers should be ensured, not only in this kind of technology training but with other up-to-date technologies that might emerge. Furthermore, computer-assisted language learning courses in the teacher preparation programs in education colleges should be regularly reviewed in order to keep up-to-date with new innovations.

The researchers suggest replicating similar studies in the Arabic context with different level of students, especially in Saudi Arabia, to find out more about the learners' views toward using this kind of virtual game. Another research suggestion is to conduct experimental studies to investigate the effect of incorporating the Second Life game in teaching various language skills.

\section{References}

Aldosemani T., \& Shepherd, C. E. (2014). Second Life to support multicultural literacy: Preservice teachers' perceptions. Tech Trends, 58(2), 46-58.

Alshumaimeri, Y. \& Bamanger, E. (2013). The effects of WebQuest writing instruction on the writing performance of Saudi male EFL learners. Procedia-Social and Behavioral Sciences, 83, 960-968.

Alshumaimeri, Y., Gashan, A. \& Bamanger, E. (2019). Virtual worlds for collaborative learning: Arab EFL learners' attitudes. World Journal on Educational Technology: Current Issues. 11(3), 198-204.

Bamanger, E. \& Alhassan, R. (2015). Exploring podcasting in English as a foreign language learners' writing performance. Journal of Education and Practice, 6(11), 63- 74.

Cooke-Plagwitz, J. (2008). New directions in CALL: An objective introduction to Second Life. CALICO Journal, $25(3), 547-557$ 
Delucia, A., Francese, R., Passero, I., \& Tortora, G. (2009). Development and evaluation of a virtual campus on Second Life: The case of Second DMI. Computers \& Education, 52(1), 220-233.

Dixon, D. H. (2014). Leveling up language proficiency through massive multiplayer online role playing games: Opportunities for English learners to receive input, modify output, negotiate meaning, and employ language-learning strategies (Master's thesis). Retrieved from ProQuest Dissertations \& Theses Global. (Order No. 1554214)

Dourda, K., Bratitsis, T., Griva, E., \& Papadopoulou, P. (2014). Content and language integrated learning through an online game in primary school: A case study. Electronic Journal of E-Learning, 12(3), 243-258.

Ertzberger, J. (2009). An Exploration of Factors Affecting Teachers' Use of Video Games as Instructional Tools. In I. Gibson, R. Weber, K. McFerrin, R. Carlsen \& D. Willis (Eds.), Proceedings of SITE 2009--Society for Information Technology \& Teacher Education International Conference (pp. 1825-1831). Charleston, SC, USA: Association for the Advancement of Computing in Education (AACE). Retrieved from http://www.editlib.org/p/30884.

Fageeh, A. (2011). At crossroads of EFL learning and culture: How to enhance cross-cultural awareness in EFL college students. Cross-Cultural Communication, 7(1), 62-72.

Gale, M. (2011). Gameplay in higher education: The use of serious games vs traditional instructional methods in learning (Doctoral dissertation). Retrieved from ProQuest Dissertations \& Theses. (UMI No. 3464449).

Gass, S., \& Selinker, L. (2001). Second language acquisition: An introductory course. Mahwah, NJ: Lawrence Erlbaum.

Grant, S. \& Clerehan, R. (2011). Finding the discipline: Assessing student activity in "Second Life." Australasian Journal of Educational Technology, 27(5), 813-828.

Hassan, R. Dzakiria, H. \& Idrus, R. (2016). Using 'second life' [sic] to develop EFL students' language learning: Opportunities and challenges. In e-Proceeding of the Global Conference on Technology in Language Learning 2015 (pp. 120-130). Kuala Lumpur, Malaysia.

Ho, C. M. L., Rappa, N. A. \& Chee, Y. S. (2009). Designing and implementing virtual enactive role-play and structured argumentations: Promises and pitfalls. Computer Assisted Language Learning, 22(5), 381-408.

Hwang, G., \& Wu, P. (2012). Advancements and trends in digital game-based learning research: A review of publications in selected journals from 2001 to 2010. British Journal of Educational Technology, 43, E6E10.

Kirriemuir, J., \& McFarlane, A. (2004). Report8: Literature Review in Games and Learning. Future Lab, Retrieved from https://telearn.archives-ouvertes.fr/hal-00190453/document

Noraddin, E., \& Neo Tse, K. (2015). Academics' attitudes toward using digital games for learning \& teaching in Malaysia. Malaysian Online Journal of Educational Technology, 2(4), 1-21.

Noraddin, E. \& Neo Tse, K. (2015). Three learning potentials in digital games: Perceptions of Malaysian university teachers. Journal of E-Learning \& Knowledge Society, 11(2), 143-160.

Papastergiou, M. (2009). Digital game-based learning in high school computer science education: Impact on educational effectiveness and student motivation. Computers \& Education, 52(1), 1-12.

Peterson, M. (2010). Massively multiplayer online role-playing games as arenas for second language learning. Computer Assisted Language Learning, 23(5), 429- 439.

Prensky, M. (2001). Digital game-based learning. New York, NY: McGraw-Hill.

Rahim, N. A. (2013). Collaboration and knowledge sharing using 3D virtual world on Second Life. Education for Information, 30(1), 1-40.

Rogerson, R. P., Nie, M., \& Armellini, A. (2012). An evaluation of the use of voice boards, e-book readers and virtual worlds in a post graduate distance learning applied linguistics and TESOL programme. Open Learning, 27(2), 103-119.

Rosman, F., Alias, N., Siraj, S., Kenayathullah, H. B., Zakaria, A. R., \& Darusalam, G. (2013). Potential of digital games in learning Bahasa Melayu vocabulary among international universities students in Malaysia: A meta-analysis of selected journals. Turkish Online Journal of Educational Technology, 12(4), 163-170.

Sanchez, J. (2007). A Sociotechnical Systems Analysis of Second Life in an Undergraduate English Course. In C. Montgomerie \& J. Seale (Eds.), Proceedings of ED-MEDIA 2007--World Conference on Educational Multimedia, Hypermedia \& Telecommunications (pp. 4254-4258). Vancouver, Canada: Association for the Advancement of Computing in Education (AACE).

Sykes, J. \& Reinhardt, J. (2013). Language at play: Digital games in second and foreign language teaching and learning. NY: Pearson Education.

Warburton, S., \& Perez-Garcia, M. (2009). 3D design and collaboration in massively multi-user virtual environments. In D. Russel (Ed.), Cases on collaboration in virtual learning environments: processes and interactions (pp.27-41). Hershey, PA: IGI Global.

Wyss, J., Lee, S., Domina, T., \& MacGillivray, M. (2014). Cotton Island: Students' learning motivation using a virtual world. Decision Sciences Journal of Innovative Education, 12(3), 219-232. doi:10.1111/dsji.12036. 